\title{
Desempenho e digestibilidade de componentes nutritivos de dietas contendo subprodutos de oleaginosas na alimentação de cordeiros ${ }^{1}$
}

\section{Performance and digestibility of nutritional components of diets containing byproducts of oleaginous in lambs feeding}

\author{
Viviane Correa Santos²; Jane Maria Bertocco Ezequiel ${ }^{3}$; Eliane da Silva Morgado4; \\ Vanessa Ruiz Fávaro ${ }^{4}$; André Pastori D’Áurea ${ }^{4}$; Severino Cavalcante de Sousa Junior ${ }^{5}$
}

\begin{abstract}
Resumo
O trabalho teve como objetivo avaliar a introdução de subprodutos de oleaginosas na alimentação de ovinos. As dietas foram compostas por 30\% de feno de capim tifton e $70 \%$ de concentrado, composto por milho em grão e farelo de soja, tortas de soja, girassol, amendoim, calcário calcítico e mistura mineral, conforme as dietas: FS - controle com farelo de soja, TS - torta de soja como parte do concentrado, TG - torta de girassol como parte do concentrado e TA - torta de amendoim como parte do concentrado. Para a avaliação do desempenho foram confinados 24 cordeiros da raça Santa Inês, machos não-castrados, desmamados com, aproximadamente, 70 dias de idade, com peso corporal médio de $19 \pm 2 \mathrm{~kg}$, utilizando-se delineamento inteiramente casualizado. Para a avaliação da digestibilidade foram utilizados oito cordeiros da raça Santa Inês machos não-castrados com aproximadamente 70 dias de idade média, peso corporal médio de $16 \mathrm{~kg}$, adotando-se o método de coleta total de fezes. $\mathrm{O}$ delineamento experimental foi em Quadrado Latino 4 x 4 e as médias comparadas pelo teste de Tukey a 5\% de probabilidade. A duração do confinamento, o ganho de peso diário, a conversão alimentar e o consumo não foram afetados ( $\mathrm{P}>0,05)$, com médias de 54,29 dias, $259 \mathrm{~g} / \mathrm{dia}, 4,29 \mathrm{~kg}$ de MS/ $\mathrm{kg}$ e 1,32 $\mathrm{kg} /$ dia, respectivamente. Não houve diferença $(\mathrm{P}>0,05)$ entre as dietas para a digestibilidade da MS, MO, PB, FDA, CT e CNF com médias de 76,23; 74,47; 76,44; 41,12; 73,00 e 90,03\%, respectivamente. A substituição parcial do farelo de soja por subprodutos de oleaginosas mostrou-se como boa alternativa protéica na alimentação de ovinos.
\end{abstract}

Palavras-chave: Ovinos, proteína, torta de amendoim, torta de girassol, torta de soja

\footnotetext{
Abstract

The aim of this work was evaluate introduction of byproducts of oleaginous in lambs feeding. Diets were composed for $30 \%$ of Tifton hay and $70 \%$ of concentrate based on corn grain, soybean meal, soybean cake, sunflower cake and peanut cake, limestone and mineral mixture, as dites: FS - control with soybean meal, TS - soybean cake as part of the concentrate, TG sunflower cake as part of the concentrate and TA - peanut cake as part of the concentrate. For performance evaluating 24 Santa Inês lambs with initial age and weight of 70 days and $19 \pm 2 \mathrm{~kg}$, according to a completely randomized

${ }^{1}$ Projeto financiado pela Fundação de Amparo à Pesquisa do Estado de São Paulo, FAPESP, São Paulo, SP.

${ }^{2}$ Prof $^{a}$ do Dept ${ }^{\circ}$ de Biologia e Zootecnia, Faculdade de Engenharia de Ilha Solteira, Universidade Estadual Paulista "Júlio de Mesquita Filho", UNESP, Ilha Solteira, SP. E-mail: vivianecorreasantos@gmail.com

${ }^{3}$ Prof $^{\mathrm{a}}$ do Dept ${ }^{\mathrm{0}}$ de Zootecnia, Faculdade de Ciências Agrárias e Veterinárias, UNESP, Jaboticabal, SP. E-mail: janembe_fcav@

${ }^{4}$ Drs. em Zootecnia, UNESP/FCAV, Jaboticabal, SP. E-mail: eliane_morgado@hotmail.com; vanessa_favaro@yahoo.com.br,

${ }^{5}$ Prof. do Dept ${ }^{\circ}$ de Zootecnia, Universidade Federal do Piauí, UFPI, Bom Jesus, PI. E-mail: sevzoo@yahoo.com.br
} yahoo.com.br andredaurea@gmail.com

* Autor para correspondência 
design. For digestive evaluate, weight Santa Inês sheep with initial age and weight of 70 days and $16 \pm$ $1.2 \mathrm{~kg}$, adapted to the use of bag, for collect feces. Animals were distributed in a replicated $4 \times 4$ Latin Square and means were compared by Tukey's test with 5\% significance level. By the performance trial, duration of confinement, weight gain, fed conversion and the dry matter intake were not affected $(\mathrm{P}>0,05)$, with averages of 54.29 days, $259 \mathrm{~g} /$ day, $4.29 \mathrm{~kg}$ of DM/ $\mathrm{kg}$ and $1.32 \mathrm{~kg} /$ day, respectively. There were no difference $\mathrm{P}>0,05$ ) for intake $\mathrm{DM}, \mathrm{OM}, \mathrm{CP}, \mathrm{CT}$ and $\mathrm{CE}$ among diets, digestibility trial with averages of $76.23 ; 74.47 ; 76.44 ; 41.12 ; 73.00$ and $93.00 \%$, respectively. There were no differences for digestibility DM, OM, CP, ADF, CT and NCF. The partial substitution of the soybean meal for byproducts of oleaginous was a good proteic alternative in the feeding of lambs.

Key words: Peanut cake, protein, soybean cake, sunflower cake, sheep

\section{Introdução}

A introdução de tortas na alimentação animal tem demonstrado ser uma alternativa alimentar viável proporcionando bons resultados. Elas apresentam grande potencial, haja vista as consideráveis concentrações de proteína e extrato etéreo, que as caracterizam como alimentos protéicos e/ou energéticos, capazes de permitir o atendimento das exigências nutricionais destas frações pelos animais.

Para a extração do óleo, dois processos são classicamente empregados. O método que utiliza hexano como solvente que é de escala industrial e caracteriza-se pela elevada eficiência, resultando o farelo, um produto com $1,5 \%$ de óleo na matéria seca. Este produto é o principal derivado resultante da industrialização de oleaginosas e o mais disponível no mercado. O processo mecânico da extração de óleo é menos eficiente e as tortas são produtos resultantes desta extração.

O rendimento na extração da torta varia de acordo com a cultivar das sementes utilizadas, uma vez que as quantidades de óleo contidas nos grãos também são muito variáveis. Salienta-se que, apesar de ser menos eficiente na retirada da fração lipídica, a extração por prensa constitui o sistema mais viável em pequena escala, por não depender das exigências de instalações e segurança inerentes ao processamento com uso de solvente. A extração do óleo por meio de prensagem mecânica, para a produção de biocombustível é uma opção econômica para minifúndios, resultando em um ingrediente pronto para ser utilizado diretamente na propriedade (SANTOS et al., 2009a).

Algumas tortas apresentam particularidades como fatores tóxicos ou antinutricionais que determinarão as quantidades máximas dentro de cada dieta e as práticas de armazenamento destas (ABDALLA et al., 2008), além de limitações como teor de fibra elevado.

Estudos recentes indicam que os subprodutos da produção do biodiesel tem características nutricionais que os tornam adequados para serem incluídos na dieta de ruminantes (ABDALLA et al., 2008; CORREIA et al., 2011; SANDERS et al., 2011). Assim, este trabalho teve como objetivo estudar a inclusão de fontes protéicas alternativas resultantes do processamento de oleaginosas destinadas à produção do biodiesel na alimentação de ovinos.

\section{Material e Métodos}

Quatro dietas isonitrogenadas (18\% de PB na MS) foram formuladas (NRC, 2007), com proporção volumoso:concentrado de 30:70 tendo sido utilizado como volumoso o feno de capim tifton moído. $\mathrm{Na}$ Tabela 1, encontra-se a composição química dos ingredientes. Os concentrados foram compostos por milho em grão moído, farelo de soja, tortas de soja, girassol e amendoim, calcário calcítico, antioxidante e mistura mineral, conforme as dietas: FS - controle com farelo de soja, TS - torta de soja como parte do concentrado, TG - torta de girassol como parte do concentrado e TA - torta de amendoim como parte do concentrado (Tabela 2 ). 
Para a avaliação do desempenho foram utilizados 24 cordeiros machos não-castrados, da raça Santa Inês, desmamados com aproximadamente 70 dias de idade, peso médio inicial de $19 \pm 2 \mathrm{~kg}$. Os cordeiros foram alojados em baias individuais, com seis repetições para cada dieta. No início do experimento, os cordeiros foram identificados, individualmente, através de colar, e receberam anti-helmíntico e suplementação de vitaminas B12, A, D, E e ferro e tiveram 20 dias de adaptação as condições experimentais. O alimento foi dividido em duas refeições: uma fornecida às 9 horas e a outra às 17 horas. $\mathrm{O}$ concentrado foi misturado ao volumoso no cocho, no momento da alimentação.

Tabela 1. Composição química dos ingredientes das dietas experimentais (\% MS).

\begin{tabular}{lcccc}
\hline & MS & EE & PB & FDN \\
\cline { 3 - 5 } Ingredientes & $\mathbf{\%}$ & & $\mathbf{\%}$ MS & \\
\hline Feno de tifton & 92,35 & 1,52 & 10,66 & 89,18 \\
Milho em grão & 88,50 & 5,9 & 9,40 & 10,50 \\
Farelo de soja & 88,02 & 1,27 & 51,86 & 27,34 \\
Torta de soja & 93,15 & 14,00 & 44,32 & 17,07 \\
Torta de girassol & 92,86 & 15,04 & 42,00 & 52,32 \\
Torta de amendoim & 92,72 & 15,38 & 46,85 & 17,50 \\
\hline
\end{tabular}

Fonte: Elaboração dos autores.

Tabela 2. Proporção dos ingredientes e composição química e energética das dietas experimentais (\% MS).

\begin{tabular}{lcccc}
\hline & \multicolumn{3}{c}{ Dietas } \\
\cline { 2 - 5 } Ingredientes (\%) & FS $^{\mathbf{1}}$ & $\mathbf{T S}^{\mathbf{2}}$ & $\mathbf{T G}^{\mathbf{3}}$ & $\mathbf{T A}^{\mathbf{4}}$ \\
\hline Feno de capim Tifton & 30,00 & 30,00 & 30,00 & 30,00 \\
Milho em grão moído & 45,40 & 45,40 & 45,40 & 45,40 \\
Farelo de soja & 23,00 & 14,00 & 14,00 & 14,00 \\
Torta de soja & - & 9,00 & - & - \\
Torta de girassol & - & - & 9,00 & - \\
Torta de amendoim & - & - & - & 9,00 \\
BHT & 0,10 & 0,10 & 0,10 & 0,10 \\
Calcário calcítico & 0,50 & 0,50 & 0,50 & 0,50 \\
Mistura mineral* & 1,00 & 1,00 & 1,00 & 1,00 \\
Total & 100,00 & 100,00 & 100,00 & 100,00 \\
\hline Composição & & & & \\
\hline Proteína bruta (\% MS) & 18,72 & 18,04 & 18,00 & 18,26 \\
Extrato Etéreo (\% MS) & 2,82 & 3,92 & 4,01 & 4,04 \\
Fibra em detergente Neutro (\% MS) & 38,24 & 39,06 & 43,97 & 39,82 \\
EM ( Mcal/Kg MS) ** & 2,51 & 2,53 & 2,51 & 2,52 \\
\hline
\end{tabular}

${ }^{1} \mathrm{FS}$ : controle com farelo de soja; ${ }^{2} \mathrm{TS}$ : formulada com torta de soja; ${ }^{3} \mathrm{TG}$ : formulada com torta de girassol; ${ }^{4} \mathrm{TA}$ : formulada com torta de amendoim.

Mistura mineral comercial para ovinos $(\mathrm{P}=60 \mathrm{~g} ; \mathrm{Ca}=100 \mathrm{~g} ; \mathrm{Na}=195 \mathrm{~g} ; \mathrm{Mg}=10 \mathrm{~g} ; \mathrm{S}=25 \mathrm{mg} ; \mathrm{Zn}=4.000 \mathrm{mg} ; \mathrm{Cu}=600 \mathrm{mg} ; \mathrm{Mn}=600 \mathrm{mg}$; $\mathrm{Fe}=1.200 \mathrm{mg} ; \mathrm{Co}=100 \mathrm{mg} ; \mathrm{I}=180 \mathrm{mg} ; \mathrm{Se}=12 \mathrm{mg} ; \mathrm{Fl}$ (máximo)=600mg)

** EM = 0,82 ED (SNIFFEN; CONNOR; VAN SOEST, 1992).

Fonte: Elaboração dos autores. 
As tortas de girassol e amendoim foram adquiridas na Empresa Sementes Esperança Comércio Importação e Exportação, situada na cidade de Jaboticabal-SP. A extração da torta de soja foi realizada na CATI - Coordenadoria de Assistência Técnica Integral/Núcleo de Produção de Sementes de Águas de Santa Bárbara-SP.

Diariamente, antes do fornecimento da alimentação pela manhã, foram recolhidas e pesadas as sobras das rações para ajuste da quantidade ofertada, visando o cálculo do consumo e da conversão alimentar. Permitiu-se $10 \%$ de sobras do total ofertado. As pesagens foram realizadas a cada 14 dias para controle do desenvolvimento dos animais e quando os primeiros animais foram abatidos as pesagens passaram a ser semanais.

No ensaio de digestibilidade foram utilizados oito cordeiros machos não-castrados, da raça Santa Inês, com aproximadamente 70 dias de idade, peso médio inicial de $16 \pm 1,2 \mathrm{~kg}$. Os cordeiros foram colocados em gaiolas individuais e adaptados para o uso de sacolas, para coleta de fezes. Cada gaiola continha comedouros e bebedouros individuais. Cada período experimental teve a duração de 15 dias sendo 10 dias de adaptação as condições experimentais e 5 dias de coleta, nos quais foram amostradas as fezes, as sobras e a ração fornecida. As fezes foram coletadas e pesadas diariamente pela manhã, homogeneizadas e retiradas amostras de $10 \%$ do total. Eram acondicionadas em embalagens de polietileno e congeladas para posterior processamento e análises laboratoriais.

As amostras do alimento fornecido, das sobras e das fezes, foram pré-secas em estufa a $55^{\circ} \mathrm{C}$, com ventilação forçada, por 72 horas. Posteriormente, foram moídas em moinho faca, dotado com peneiras de crivos de $1 \mathrm{~mm}$, para determinação dos teores de matéria seca (MS), cinzas (CZ), proteína bruta (PB), extrato etéreo (EE), segundo AOAC (1995), fibra em detergente neutro corrigida para cinzas e proteína (FDNcp), fibra em detergente ácido corrigida para cinzas e proteína (FDAcp), utilizando soluções propostas por Van Soest e Wine (1967) e a digestão realizada em autoclave $\left(0,5 \mathrm{kgf} / \mathrm{cm}^{2}, 111^{\circ} \mathrm{C}\right.$ por 50 minutos), de acordo com procedimento adaptado de Pell e Schofield (1992). Os valores de carboidratos totais (CT) foram obtidos pela equação: $100-(\% \mathrm{~PB}+\% \mathrm{EE}+\% \mathrm{CZ})$, enquanto os carboidratos não fibrosos (CNF), pela diferença entre CT e FDN e os nutrientes digestíveis totais (NDT) foram obtidos conforme recomendações de Sniffen, Connor e Van Soest (1992).

A partir do coeficiente de digestibilidade da energia bruta (EB), obtiveram-se os valores de energia digestível (ED) e, posteriormente, a energia metabolizável (EM), estimada conforme a recomendação de Sniffen, Connor e Van Soest (1992): $\mathrm{EM}=0,82 \mathrm{ED} ; \mathrm{ED}=(\mathrm{EB}$ ingerida $\mathrm{x}$ CDEB)/100.

No experimento de desempenho, o delineamento estatístico utilizado foi o inteiramente casualizado, com quatro dietas e seis repetições e para o ensaio de digestibilidade foi em dois quadrados latinos (4 $\mathrm{x} 4$ ), com quatro dietas e quatro períodos, ocorrendo simultaneamente. Os resultados obtidos foram submetidos à análise de variância adotando o procedimento estatístico PROC GLM (SAS, 2008). As médias foram comparadas pelo teste de Tukey, a $5 \%$ de probabilidade.

\section{Resultados e Discussão}

O ganho de peso médio diário, o consumo de matéria seca e a conversão alimentar dos cordeiros terminados em confinamento com dietas contendo tortas de soja, girassol e de amendoim não diferiram entre o grupos. O tempo de confinamento também não diferiu entre os grupos, com média de 54,29 dias. O principal argumento pela não detecção de diferenças entre esses resultados do tempo de confinamento pode estar relacionado ao elevado coeficiente de variação, o que reduziu as chances de identificar diferenças mínimas significativas (Tabela 3). 
Vale ressaltar que menores períodos de confinamento reduzem a idade ao abate e favorecem as carcaças em termos quali-quantitativos, além de representar menores custos de produção e proporcionar maior rotatividade de animais no confinamento/ano, amortizando mais rapidamente as despesas com instalações e alimentação. Santos et al. (2009b) concluiu que dietas de custo mínimo em confinamentos, são aquelas com alta proporção de concentrado.

Tabela 3. Pesos inicial e final, duração do confinamento (DC), ganho de peso diário (GPD), consumo de matéria seca (CMS) e conversão alimentar (CA) de cordeiros alimentados com subprodutos de oleaginosas.

\begin{tabular}{lcccccc}
\hline & \multicolumn{7}{c}{ Dietas } \\
\cline { 2 - 5 } Variável & $\mathbf{F S}^{\mathbf{1}}$ & $\mathbf{T S}^{\mathbf{2}}$ & $\mathbf{T G}^{\mathbf{3}}$ & $\mathbf{T A}^{\mathbf{4}}$ & $\mathbf{P}$ & $\mathbf{C V}(\mathbf{\%})$ \\
\cline { 1 - 5 } Peso inicial & 19,58 & 19,43 & 18,42 & 18,98 & 0,8384 & 11,69 \\
Peso final & 32,54 & 32,55 & 32,76 & 32,98 & 0,6429 & 2,04 \\
DC (dias) & 50,40 & 50,67 & 60,40 & 55,67 & 0,6067 & 25,25 \\
GPD (kg/animal/dia) & 0,277 & 0,261 & 0,244 & 0,252 & 0,5805 & 14,92 \\
CMS (kg/dia) & 1,365 & 1,292 & 1,329 & 1,298 & 0,8318 & 11,14 \\
CA (kg de MS/ kg de ganho) & 4,13 & 4,09 & 4,65 & 4,27 & 0,4121 & 11,89 \\
\hline
\end{tabular}

${ }^{1} \mathrm{FS}$ : controle com farelo de soja; ${ }^{2} \mathrm{TS}$ : formulada com torta de soja; ${ }^{3} \mathrm{TG}$ : formulada com torta de girassol; ${ }^{4} \mathrm{TA}$ : formulada com torta de amendoim.

Médias nas linhas não diferem entre si pelo teste de Tukey $(\mathrm{p}>0,05)$

$\mathrm{P}=$ probabilidade

$\mathrm{CV}=$ coeficiente de variação.

Fonte: Elaboração dos autores.

O consumo de matéria seca não foi afetado $(\mathrm{P}>0,05)$ pelas dietas. Essa variável é um importante fator no desempenho de ovinos em confinamento, sendo considerada o ponto determinante do aporte de nutrientes necessários para o atendimento das exigências de mantença e de ganho de peso dos animais (SNIFFEN et al., 1993).

A média do consumo de matéria seca durante todo o ensaio foi de $1,321 \mathrm{~kg} /$ dia, e encontra-se na faixa recomendada pelo NRC (2007) para ovinos desta categoria (1,0 a 1,3 kg/dia). O consumo do presente trabalho foi semelhante $(1,290 \mathrm{~kg} /$ dia) ao encontrado por Queiroz et al. (2008) que alimentaram cordeiros Santa Inês com dietas contendo $10 \%$ de volumoso e $90 \%$ de concentrado com torta de amendoim.

O ganho de peso médio diário e a conversão alimentar não diferiram entre os grupos, o que demonstra a possibilidade de utilização de qualquer uma das fontes proteicas avaliadas (Tabela 3). O uso de uma ou de outra, estará na dependência do custo de aquisição e da disponibilidade no mercado.

$\mathrm{O}$ ganho de peso médio obtido com as quatro dietas foi de $259 \mathrm{~g} /$ dia. O NRC (2007) sugere ganho de peso diário entre 200 a 250 g para cordeiros de até quatro meses de idade, com $30 \mathrm{~kg}$ de peso corporal, o que foi observado neste experimento. Queiroz et al. (2008) verificaram ganhos médios diários de 320 g em cordeiros da raça Santa Inês, alimentados com dietas contendo torta de amendoim.

A conversão alimentar, que compreende a quantidade de matéria seca ingerida para produzir um $\mathrm{kg}$ de peso corporal, foi em média 4,29 $\mathrm{kg}$ de matéria seca. Já Queiroz et al. (2008) obtiveram valor médio de 3,46, em cordeiros Santa Inês alimentados com torta de amendoim.

Carvalho et al. (2007) observaram menores ganhos de peso diário $(228 \mathrm{~g})$ e melhor conversão alimentar (4,00) nos animais que receberam $70 \%$ 
de concentrado na dieta. A conversão alimentar pode ser influenciada por vários fatores, como a densidade energética e qualidade da fibra da dieta, idade, estado sexual e comparação de ganho, tornando difícil a comparação desses valores entre os diversos trabalhos (RESTLE et al., 2001).

Não foram observados efeitos $(\mathrm{P}>0,05)$, dos subprodutos de oleaginosas sobre o consumo de matéria seca, matéria orgânica, proteína bruta, carboidratos totais e energia bruta (Tabela 4).

Tabela 4. Consumo de nutrientes e de energia bruta (EB) em função das dietas com subprodutos de oleaginosas

\begin{tabular}{|c|c|c|c|c|c|c|}
\hline \multicolumn{7}{|c|}{ Dietas } \\
\hline Variável & FS $^{1}$ & $\mathbf{T S}^{2}$ & $\mathrm{TG}^{3}$ & $\mathbf{T A}^{4}$ & $\mathbf{P}$ & CV $(\%)$ \\
\hline MS, (kg/dia) & 1,245 & 1234 & 1,265 & 1,282 & 0,0021 & 6,84 \\
\hline $\mathrm{MO},(\mathrm{kg} / \mathrm{dia})$ & 1,062 & 1,055 & 1,082 & 1,093 & 0,0021 & 6,85 \\
\hline $\mathrm{PB},(\mathrm{kg} / \mathrm{dia})$ & 0,216 & 0,224 & 0,221 & 0,231 & 0,0019 & 6,85 \\
\hline $\mathrm{EE},(\mathrm{kg} / \mathrm{dia})$ & $0,038 b$ & $0,034 \mathrm{~b}$ & $0,056 \mathrm{a}$ & $0,055 \mathrm{a}$ & $<0,0001$ & 6,83 \\
\hline FDNcp, (kg/dia) & $0,503 \mathrm{a}$ & $0,468 \mathrm{ab}$ & $0,479 \mathrm{ab}$ & $0,434 \mathrm{~b}$ & 0,0011 & 6,91 \\
\hline FDAcp, (kg/dia) & $0,148 \mathrm{c}$ & $0,171 b$ & $0,190 \mathrm{a}$ & $0,166 b$ & 0,0003 & 7,00 \\
\hline CT, (kg/dia) & 0,808 & 0,801 & 0,807 & 0,805 & 0,0024 & 6,87 \\
\hline CNF (kg/dia) & $0,306 \mathrm{~b}$ & $0,333 b$ & $0,328 b$ & $0,372 \mathrm{a}$ & 0,0006 & 6,94 \\
\hline EB (Mcal/kg dia) & 4,840 & 4,4873 & 4,743 & 4,966 & 0,8838 & 16,12 \\
\hline
\end{tabular}

Matéria seca (MS), matéria orgânica (MO), proteína bruta (PB), extrato etéreo (EE), fibra em detergente neutro (FDNcp), fibra em detergente ácido (FDAcp), carboidratos totais (CT), carboidratos não fibrosos (CNF), energia bruta (EB).

${ }^{1} \mathrm{FS}$ : controle com farelo de soja; ${ }^{2} \mathrm{TS}$ : formulada com torta de soja; ${ }^{3} \mathrm{TG}$ : formulada com torta de girassol; ${ }^{4} \mathrm{TA}$ : formulada com torta de amendoim.

Médias seguidas por letras diferentes, nas linhas, diferem entre si pelo teste de Tukey $(\mathrm{p}<0,05)$

$\mathrm{P}=$ probabilidade

$\mathrm{CV}=$ coeficiente de variação.

Fonte: Elaboração dos autores.

Santos et al. (2009a), estudando a inclusão de torta de canola na alimentação de cordeiros da raça Santa Inês, observaram ingestão de $1,492 \mathrm{~kg} \mathrm{MS/}$ dia, com dietas contendo $60 \%$ de concentrado.

O consumo de PB mostrou-se similar entre as dietas, com valor médio de $0,223 \mathrm{~kg} /$ dia, semelhante ao relatado por Santos et al. (2009a), que verificaram ingestão de $0,242 \mathrm{~kg} /$ dia; e superior ao obtido por Urano et al. (2006), que relataram valor médio de 184 g/dia, em cordeiros Santa Inês, alimentados com soja em grãos, como parte da dieta. A inclusão das tortas de oleaginosas nas dietas não promoveu mudanças nos consumos de proteína bruta, porque as dietas foram isonitrogenadas e o consumo de matéria seca foi semelhante. Para o consumo de proteína bruta os valores obtidos neste trabalho estão próximos ao recomendado pelo NRC (2007), que é de $234 \mathrm{~g} \mathrm{PB/dia,} \mathrm{para} \mathrm{ovinos} \mathrm{desta} \mathrm{categoria.}$ Esta resposta ocorreu, provavelmente, em virtude da maior seletividade dos animais pelos subprodutos, uma vez que o incremento de oleaginosas na dieta melhora o desenvolvimento da microbiota ruminal e o processo de fermentação (SANTOS et al., 2009a).

O consumo de MS é altamente relacionado ao consumo de FDN do alimento e das dietas, porque a fermentação e a passagem da FDN pelo retículorúmen são mais lentas que outros constituintes dietéticos, tendo grande efeito no enchimento e sobre o tempo de permanência no rúmen, comparado aos componentes não fibrosos do alimento (VAN SOEST, 1994). No entanto, apesar do consumo de FDN ter sido afetado $(\mathrm{P}<0,05)$ 
pela inclusão dos subprodutos de oleaginosas, o consumo de matéria seca não diferiu $(\mathrm{P}>0,05)$ entre as fontes. É provável que o tamanho da fibra da fração da torta de girassol, que foi finamente moída para subsequente misturas nas rações, promoveu um passagem normal no trato digestório sem causar enchimento rumino-reticular.

Os consumos de EE pelos cordeiros alimentados com as dietas com torta de girassol e torta de amendoim foram superiores $(\mathrm{P}<0,05)$ aos da dieta contendo torta de soja e o controle, consequência da composição da dieta, ou seja, os maiores consumos de EE observados com as dietas contendo torta de girassol e amendoim, pode ser devido às diferenças nos teores desse nutriente entre as dietas (Tabela 1), desde que não houve diferenças nos consumos das dietas experimentais. Entretanto, os teores de EE das dietas experimentais foram inferiores a $5,1 \%$; valores que não comprometem os microrganismos ruminais.

Os CNF foram mais consumidos $(\mathrm{P}<0,05)$ pelos cordeiros alimentados com a dieta contendo torta de amendoim, em relação aos demais, devido ao maior teor do nutriente nesta dieta.

Os coeficientes de digestibilidade da MS, MO, $\mathrm{PB}, \mathrm{FDA}, \mathrm{CT}, \mathrm{CNF}$ e EB, variaram pouco entre as dietas e não apresentaram diferenças $(\mathrm{P}>0,05)$ entre si (Tabela 5). As médias obtidas para a digestibilidade da MS, MO e CT foram superiores àquelas observadas por Santos et al. (2009a), de 66,$75 ; 68,75$ e $66,67 \%$, em dietas contendo grãos, farelo e torta de canola, respectivamente.

Tabela 5. Digestibilidade dos nutrientes, teores de nutrientes digestíveis totais (NDT) e energia metabolizável (EM) das dietas com subprodutos de oleaginosas.

\begin{tabular}{lllllll}
\hline Dietas & \multicolumn{7}{l}{ TS $^{\mathbf{1}}$} & $\mathbf{T S}^{\mathbf{2}}$ & $\mathbf{T G}^{\mathbf{3}}$ & $\mathbf{T A}^{\mathbf{4}}$ & $\mathbf{P}$ & $\mathbf{C V}(\mathbf{\%})$ \\
\cline { 1 - 5 } Variável & 76,91 & 76,82 & 75,35 & 75,82 & 0,0018 & 2,70 \\
CDMS & 75,13 & 75,05 & 73,58 & 74,12 & 0,0014 & 2,93 \\
CDPB & 76,19 & 77,30 & 75,76 & 76,52 & 0,0180 & 3,15 \\
CDEE & $89,82 \mathrm{ab}$ & $87,89 \mathrm{~b}$ & $91,87 \mathrm{a}$ & $91,96 \mathrm{a}$ & 0,0226 & 2,11 \\
CDFDN & $64,07 \mathrm{a}$ & $62,32 \mathrm{a}$ & $58,18 \mathrm{ab}$ & $53,73 \mathrm{~b}$ & 0,0013 & 7,13 \\
CDFDA & 37,32 & 44,57 & 45,14 & 37,44 & 0,0014 & 14,70 \\
CDCT & 74,14 & 73,98 & 71,76 & 72,15 & 0,0007 & 3,18 \\
CDCNF & 90,71 & 89,26 & 90,48 & 89,66 & 0,0816 & 4,16 \\
CDEB & 72,81 & 74,77 & 74,22 & 74,92 & 0,0348 & 3,89 \\
NDT & $83,34 \mathrm{~b}$ & $85,60 \mathrm{ab}$ & $87,55 \mathrm{a}$ & $87,66 \mathrm{a}$ & 0,0011 & 2,55 \\
EM (Mcal/kg MS) & 2,51 & 2,53 & 2,51 & 2,52 & 0,7369 & 17,93 \\
\hline
\end{tabular}

Matéria seca (MS), matéria orgânica (MO), proteína bruta (PB), extrato etéreo (EE), fibra em detergente neutro (FDN), fibra em detergente ácido (FDA), carboidratos totais (CT), carboidratos não fibrosos (CNF), energia bruta (EB) energia bruta.

${ }^{1} \mathrm{FS}$ : controle com farelo de soja; ${ }^{2} \mathrm{TS}$ : formulada com torta de soja; ${ }^{3} \mathrm{TG}$ : formulada com torta de girassol; ${ }^{4} \mathrm{TA}$ : formulada com torta de amendoim.

Médias seguidas por letras diferentes, nas linhas, diferem entre si pelo teste de Tukey $(\mathrm{p}<0,05)$

$\mathrm{CV}=$ coeficiente de variação.

Fonte: Elaboração dos autores.

Beran et al. (2007), estudaram a torta de girassol, com uma e duas prensagens, para determinar a digestibilidade de componentes nutricionais não- degradados no rúmen, por meio da técnica dos três estágios. As digestibilidades da MS e MO, foram superiores às do presente trabalho, com valores 
médios de $88,49 \%$ e $95,41 \%$, respectivamente. Esta superioridade de digestibilidade encontrada por estes autores, provavelmente, foi em virtude da granulometria ou de alguma desestruturação química decorrente do aumento da temperatura no processo de prensagem.

Os coeficientes de digestibilidade da MS observados podem relacionar-se à maior concentração de energia, em consequência da elevação dos carboidratos não fibrosos, em relação aos carboidratos estruturais. Uma vez que os carboidratos não fibrosos apresentam digestibilidade acima de $90 \%$ e os carboidratos estruturais, próxima de $50 \%$, pode-se verificar maior digestão da MS, pois, geralmente, o incremento dos níveis energéticos das dietas proporciona melhoria da digestibilidade. Resultado semelhante foi encontrado por Agy et al. (2012), quando avaliaram a introdução de $8 \%$ de torta de girassol em rações com 2,1 Mcal EM/Kg de MS, para cabritos jovens, e verificaram coeficientes de digestibilidade da MS de 72,3\%.

Os resultados obtidos para a digestibilidade da PB não diferiram entre si. As dietas experimentais continham teores de $\mathrm{PB}$ ao redor de $18 \%$, o que parece ter contribuído para seu maior desaparecimento e, portanto, para um CDPB de 76,19\% para (FS), $77,30 \%$ para (TS), 75,76\% para (TG) e 76,52\% para (TA). Segundo Petit e Tremblay (1992), dietas com elevados teores de PB poderiam proporcionar menor digestibilidade aparente. Os resultados encontrados neste experimento, foram semelhantes aos de Santos et al. (2009a), que constataram média de $72,03 \%$ de CDPB, para grãos e subprodutos da canola.

A ausência de efeito das dietas sobre o CDPB permite inferir que as tortas de oleaginosas oriundas da produção do biodiesel podem substituir o farelo de soja sem ocorrer alterações na digestibilidade da PB.

Há relatos que, ao incluir fontes de oleaginosas na dieta de ruminantes há redução no aproveitamento da proteína (QUEIROZ et al., 2008); no entanto, neste trabalho não houve efeito $(\mathrm{P}>0,05)$ sobre a digestibilidade da proteína. Correia et al. (2011) ao avaliarem a introdução de tortas de amendoim e girassol sobre o consumo e digestibilidade aparente total não observaram diferenças na digestibilidade da proteína.

Os resultados para a digestibilidade da FDN e FDA, com este nível médio de 2,52 Mcal de EM/ $\mathrm{kg}$ MS nas dietas, pode ser atribuído à adição excessiva de amido às rações, que promove efeito depressivo sobre a digestibilidade ruminal da fibra e alterações nas condições ruminais. Coelho da Silva e Leão (1979) também relataram que a adição de concentrado às dietas produz mudanças no processo de digestão e no metabolismo dos nutrientes, devido às interações entre os alimentos, denominadas efeito associativo.

$O$ coeficiente de digestibilidade da FDN foi maior $(\mathrm{P}<0,05)$ nas dietas com torta de soja $\mathrm{e}$ controle. Este fato pode ser atribuído ao aumento da eficiência ruminal, provavelmente, em virtude da maior disponibilidade de aminoácidos para biossíntese ruminal e, possivelmente, um melhor aproveitamento da fibra desta oleaginosa. Muitos fatores levam a uma diminuição da digestão da FDN, entre eles o conteúdo de óleo das dietas. O óleo que foi disponibilizado, ou seja, liberado no meio ruminal, pode vir a provocar diminuição da eficiência das bactérias fibrolíticas (PETIT et al., 1997). Isto foi observado nas dietas inerentes à torta de girassol e ao amendoim.

O valor estimado de NDT da dieta controle foi menor $(\mathrm{P}<0,05)$ em relação às dietas contendo torta de girassol e amendoim, sendo as exigências energéticas de cordeiros, geralmente mais elevadas do que o de outras espécies de ruminantes. A utilização destas tortas poderia ser recomendada para elevar a densidade energética das dietas, desde que as demais variáveis estudadas não fossem influenciadas pela sua introdução substitutiva. 


\section{Conclusões}

Do ponto de vista da digestibilidade dos nutrientes, as dietas contendo subprodutos de oleaginosas podem ser utilizadas como parte da dieta de cordeiros ao nível de 9\%, mesmo havendo diferenças na composição desses ingredientes, principalmente em função da velocidade de degradação ruminal das diferentes frações do alimento.

\section{Referências}

ABDAlla, A. L.; SILVA FILHO, J. C.; GODOY, A. R.; CARMO, C. A.; EDUARDO, J. L. P. Utilização de subprodutos da indústria de biodiesel na alimentação de ruminantes. Revista Brasileira de Zootecnia, Viçosa, MG, v. 37, p. 260-268, 2008. Suplemento Especial.

AGY, M. S. F. A.; OLIVEIRA, R. L.; RIBEIRO, C. V. D. M.; RIBEIRO, M. D.; BAGALDO, A. R.; ARAÚJO, G. G. L.; PINTO, L. F. B.; RIBEIRO, R. D. X. Sunflower cake from biodiesel production fed to crossbred Boer kids. Revista Brasileira de Zootecnia, Viçosa, MG, v. 41, n. 1, p. 123-130, 2012.

ASSOCIATION OF OFFICIAL ANALYTICAL CHEMISTRY - AOAC. Official methods of analysis. 16. ed. Arlington: Patrícia Cunniff, 1995. 1025 p.

BERAN, F. H. B.; SILVA, L. D. F.; RIBEIRO, E. L. A.; ROCHA, M. A.; EZEQUIEL, J. M. B.; CORREA, R. A.; CASTRO, V. S.; SILVA, K. C. F. Avaliação da digestibilidade de nutrientes, em bovinos, de alguns alimentos concentrados pela técnica de três estádios. Revista Brasileira de Zootecnia, Viçosa, MG, v. 36, n.1, p. 130-137, 2007.

CARVALHO, S.; BROCHIER, M. A.; PIVATO, J.; VERGUEIRO, A.; TEIXEIRA, R. C.; KIELING, R. Desempenho e avaliação econômica da alimentação de cordeiros confinados com dietas contendo diferentes relações volumoso:concentrado. Ciência Rural, Santa Maria, v. 37, n. 5, p. 1411-1417, 2007.

COELHO DA SILVA, J. F.; LEÃO, M. I. Fundamentos de nutrição dos ruminantes. Piracicaba: Livroceres, 1979. $380 \mathrm{p}$.

CORREIA, B. R.; OLIVEIRA, R. L.; JAEGER, S. M. P. L.; BAGALDO, A. R.; CARVALHO, G. G. P.; OLIVEIRA, G. J. C.; LIMA, F. H. S. Consumo, digestibilidade e $\mathrm{pH}$ ruminal de novilhos submetidos a dietas com tortas oriundas da produção do biodiesel em substituição ao farelo de soja. Arquivo Brasileiro de
Medicina Veterinária e Zootecnia, Belo Horizonte, v. 63, n. 2, p. 356-363, 2011.

NATIONAL RESEARCH COUNCIL - NRC. Committee on animal nutritin. Nutrient requirements of small ruminants. Sheep, goats, cervids and new world Camelids. Washington, D.C.: National Academies Press, 2007. $384 \mathrm{p}$.

PELL, A. N.; SCHOFIELD, P. Computerized monitoring of gas production to measure forage digestion in vitro. Journal of Dairy Science, Madison, v. 76, n. 4, p. 10631073, 1992.

PETIT, H. V.; RIOUX, R.; D’OLIVEIRA, P. S.; PRADO, I. N. Performance of growing lambs fed grass silage with raw or extrused soybean or canola seeds. Canadian Journal of Animal Science, Sherbrooke, v. 77, n. 3, p. 455-463, 1997.

PETIT, H. V.; TREMBLAY, G. F. In situ degradability of fresh grass conserved under different harvesting methods. Journal of Dairy Science, Madison, v. 75, n. 4, p. 774-781, 1992.

QUEIROZ, M. A. A.; SUSIN, I.; PIRES, A. V.; MENDES, C. Q.; GENTIL, R. S. G.; ALMEIDA, O. M.; AMARAL, R. C.; MOURÃO, G. B. Desempenho de cordeiros e estimativa da digestibilidade do amido de dietas com diferentes fontes protéicas. Pesquisa Agropecuária Brasileira, Brasília, v. 43, n. 9, p. 1193-1200, 2008.

RESTLE, J.; NEUMANN, M.; ALVES FILHO, D. C.; PASCOAL, L. L.; ROSA, J. R. P.; MENEZES, L. F. G. de; PELLEGRINI, L. G. de. Terminação em confinamento de vacas e novilhas sob dietas com ou sem monensina sódica. Revista Brasileira de Zootecnia, Viçosa, MG, v. 30, n. 6, p. 1801-1812, 2001.

SANDERS, D. M.; OLIVEIRA, R. L.; MOREIRA, E. L. T.; JUCÁ, A. F.; SILVA, T. M.; PINTO, L. F. B.; MACOME, F. M.; BAGALDO, A. R. Morfometria da mucosa ruminal de cordeiros Santa Inês alimentados com níveis de torta de dendê (Elaeis guineesis), oriunda da produção do biodiesel. Semina. Ciências Agrárias, Londrina, v. 32, n. 3, p. 1169-1178, 2011.

SANTOS, V. C.; EZEQUIEL, J. M. B.; OLIVEIRA, P. S. N.; GALATI, R. L.; BARBOSA, J. C. Consumo e digestibilidade em ovinos alimentados com grãos e subprodutos da canola. Revista Brasileira de Saúde e Produção Animal, Salvador, v. 10, n. 1, p. 96-105, 2009a.

SANTOS, V. C.; EZEQUIEL, J. M. B.; PINHEIRO, R. S. B.; BARBOSA, J. C.; GALATI, R. L. Características de carcaça de cordeiros alimentados com grãos e subprodutos da canola. Acta Scientiarum Animal Science, Maringá, v. 31, n. 4, p. 389-395, 2009 b. 
SNIFFEN, C. J.; BEVERLY, R. W.; MOONEY, C. S.; ROE, M. B.; SKIDMORE, A. L. Nutrient requirement versus supply in dairy cow: strategies to account for variability. Journal of Dairy Science, Madison, v. 76, n. 10, p. 3160-3178, 1993.

SNIFFEN, C. J.; CONNOR, J. D.; VAN SOEST, P. J. A net carbohydrate and protein system for evaluating cattle diets: II. Carbohydrate and protein availability. Journal of animal Sicence, Madison, v. 70, n. 11, p. 3562-3577, 1992.

STATISTICALANALYSIS SYSTEM - SAS. SAS user 's: guide statistic. Cary: SAS, 2008. 74 p.
URANO, F. S.; PIRES, A. V.; SUSIN, I.; MENDES, C. Q.; RODRIGUES, G. H.; ARAUJO, R. C.; MATTOS, W. R. S. Desempenho e características da carcaça de cordeiros confinados alimentados com grão de soja. Pesquisa Agropecuária Brasileira, Brasília, v. 41, n. 10, p. 1525-1530, 2006.

VAN SOEST, P. J. Nutritional ecology of the ruminant. 2. ed. Ithaca: Cornell, 1994. 476 p.

VAN SOEST, P. J.; WINE, R. H. Use of detergents in analysis of fibrous feeds. IV. Determinations of plant cell-wall contituents. Journal of the Association Official Analytical Chemistry, Washington, v. 50, n. 50, p. 55, 1967. 